\title{
Cultural Inheritance in the Transformation of Chinese Art Education
}

\author{
Lin Ma \\ Aba Teachers University; Aba Sichuan 623002 China.
}

\begin{abstract}
With the continuous progress of national society, culture has been developing with the change of times. For Chinese art education, Chinese art education has been transformed from elite education of small audiences into education for the public. The concept of Chinese art education has also undergone a great transformation. Many scholars also put forward very advanced teaching ideas on the cultural inheritance in the transformation of art education. This is ecological cultural inheritance. This paper mainly analyzes the teaching concept of ecological culture inheritance by discussing the cultural inheritance in the transformation of Chinese art education, so as to explore a cultural inheritance road of art education with Chinese characteristics.
\end{abstract}

Keywords: Art education; cultural heritage.

\section{Reflections on Art Education in the Process of Audience Group Transformation}

Realistic problems that art education must face in the transformation process. When we started to discuss the topic of cultural inheritance in the transformation of Chinese art education, we first had to face the concept of what is art education. Based on the definition of art education concept by some famous scholars at home and abroad, we can know that art education is an education method with a very clear goal for future development direction, and it has a clear expected effect for society, rather than being developed in a straight line alone. Art education is an education model that presents a multi-angle, multi-direction and multi-dimensional with the development of social diversity. It is of great concern for the development of art talent cultivation in today's society, and this ideal and reality of education will be greatly reformed and changed with the continuous progress and development of society. The transformation of art education, fundamentally speaking, is also a transformation of the way of cultivating art talents in China.

In the past, the purpose of art education was mainly to train a few people with artistic talent. Such niche education can also be called elite education, and the main purpose is to cultivate elite figures in a certain art field. However, with the continuous reform and transformation in the field of art education, art education is not limited to the elite education of the niche, but focuses on a large-scale education model of the public. In this mode of art education, students studying art are not expected to become leaders in this field. The main purpose of this model is to popularize aesthetic education to the public. Therefore, the education model of art is very helpful to improve the aesthetic level of the whole people.

\section{Education Status Quo in the Transformation Process of Art Education}

China's education system reform has been carried out for many years. With the continuous progress of education system reform and the continuous expansion of university scale, the university has gained more autonomous rights. This provides a convenient condition for education transformation to some extent. Education especially art education is no longer the elite education serving the niche. It's more of an education for the general public. As a result, for art education in universities, the number of art majors is growing every year. The bar for art education has dropped, and more people are learning about art. But this creates a bad phenomenon. Many universities have expanded their recruitment of art majors. But they are not for students' art study. Many students apply to study art education. But that doesn't mean they love art. The actual situation is not optimistic. It is difficult for art education with utilitarian purpose to inherit the culture in art education. 
During the transformation process of art education, education audience group has changed, and the corresponding cultural inheritance will inevitably change. In the past, the elite education students in the minority education usually learn relevant knowledge systematically, and they are more profound and comprehensive in cultural inheritance. The students of education, an art widely accepted, tend to have an appreciation and experience of culture, and a self-understanding and perception of culture. In order to adapt to the development of modern society and enable students to better inherit and develop traditional culture in art education, we must develop education mode that can adapt to modern society. Only in this way can we combine traditional culture with modern education and let traditional culture play its due value. This is something that educators and the whole education system should be thinking about.

\section{The Multi-Dimensional Inheritance in the Education Transformation of Chinese Art}

Combing and absorbing the traditional art culture. Chinese culture is extensive and profound, and Chinese people's reflection on aesthetics has been derived from the totem worship in ancient times. For example, the depiction of the human head and snake body of $\mathrm{Fu} \mathrm{Xi} \mathrm{Nu} \mathrm{Wa}$, Pan Gu's creation of the sky and the earth, also appears with the figure of human head and snake body. The description of these images all reflects people's aesthetic awareness of totem symbols in ancient times. On the other hand, it is also a way of thinking of artistic creation. The symbols in Chinese pottery civilization and bronze ware civilization were inseparable from the social and political forms at that time. The emergence of various kinds of cultural ideology fully shows that the development of Chinese art and culture are symbiotic and co-growing, and the emergence of these art forms also promotes the prosperity of ancient Chinese culture and art.

The inheritance and continuation of the spiritual level in the traditional art thoughts. Among Chinese traditional thoughts education, courtesy and noble character are regarded as the spirit of a gentleman. In the philosophical thought system of ancient Chinese Laozi and Zhuangzi, we can see the rich connotation of humanistic art. And their cultural idea of harmony between man and nature is exactly consistent with the core values of contemporary ecological aesthetics. Cultural inheritance in art education is not only a record of Chinese traditional culture, but more importantly, a profound understanding and inheritance of the connotation of such excellent traditional culture. We should be able to perceive the profound thoughts, feelings and aesthetic ideas in these excellent traditional cultures.

\section{4. "Ecological" Cultural Inheritance in the Transformation of Art Education}

The basis and mode of realizing "ecological cultural inheritance". In the transformation of Chinese art education, cultural inheritance is always at the core. Therefore, in the process of the transformation of the art education, how to ensure that the culture is not lost in the process of inheritance, and that the culture remains intact is a realistic problem we need to face. One good mode of inheritance is to develop ecological cultural inheritance. The ecological cultural inheritance mentioned here mainly refers to the harmonious development of human and nature. It's a multi-angle, multi-dimensional connection. Through the development mode of ecological cultural inheritance, the integrity and comprehensiveness of culture can be ensured in the process of cultural inheritance. In the process of ecological cultural inheritance, it pays more attention to the perception of the spirit of traditional Chinese culture and art. It is a combing of Chinese traditional culture, which well reflects the essence of Chinese traditional art.

In today's society, sinology seems to have become a cultural trend, its interpretation and dissemination of traditional Chinese culture beyond the scope of culture. Over-interpretation of traditional Chinese culture has lacked the core meaning of culture and art. As the Times are progressing and the society is developing, the inheritance of Chinese traditional culture should also keep pace with The Times and combine with modern art education. In the process of teaching art 
education, we should boldly abandon the part of traditional culture that is not suitable for the current social development. We should inherit its use value from the feasibility of culture and art. Therefore, for the cultural inheritance mode in the transformation of art education, the ecological cultural inheritance is very important. Only by adopting ecological cultural inheritance can we get rid of the disadvantages of traditional cultural inheritance in the process of art education transformation, so as to achieve better cultural inheritance effect.

The inheritance of ecological culture in multicultural environment. The development of human culture presents a trend of diversified development, especially in today's society. With the increasingly diversified global economy, society and ideology, the development of human culture is more diversified. This is also the inevitable trend of social objective development. Because it is not only different in region and race, but also different in region and different in religious belief and ideology. Therefore, in the aspect of cultural and artistic inheritance, the diversified situation is also an objective cultural form. One of the advantages of this situation is the integration of cultures between different nationalities. They absorb some valuable and good exotic cultures from the cultures of various nations in the world, and then can promote the further development of their own cultures. This is very beneficial to the common development of the world's multi-culture. While inheriting and developing multi-culture, we must clearly recognize that the development of multi-culture has its own cultural characteristics of different nations. Its establishment itself is a kind of absorption and communication for the recognition of different cultures in different regions. We should build on this foundation to form a situation of multi-cultural coexistence. However, on the basis of the coexistence and development of multi-cultures, the communication and integration between different cultures are not blindly carried out. On the basis of cultural inheritance and development, we should select the parts that are conducive to the development of the subject culture to absorb and integrate. We should be able to absorb the essence of multi-culture on the basis of the consciousness of the subject of national culture, so as to realize the ecological cultural inheritance.

New mode of ecological culture inheritance. The development of culture is not invariable, but develops in the constant change. There is no end to the development of culture. As long as human civilization exists, there will be cultural development. The development of culture is single and forward in time, but it is multi-dimensional in the level of development. Therefore, in terms of cultural inheritance, if we want to have a comprehensive and complete cultural inheritance, we need to know the specific context of cultural development and the different disciplines among cultures. We should make clear the specific direction of cultural inheritance. At the same time, on the basis of defining the cultural context, we should conduct a multi-dimensional in-depth study and discussion on each level of cultural development. We should intersect and integrate the cultural development in different dimensions to form a whole cultural development. In the multi-dimensional cultural ecological pattern, we're going to the development of Chinese art education and the cultural link to the actual situation, according to the object and direction of the art education to cultivate as well as the specific teaching strategies, to formulate detailed, scientific and effective teaching plan, to be targeted to scientific cultural heritage to absorb and draw lessons from. In this way, the interrelation between multi-subjects and multi-cultures can expand the range of knowledge of students, which is also conducive to the cultivation of students' innovative thinking. Through this multi-level and interdisciplinary teaching mode, we can make Chinese art education have a comprehensive cultural development demand for the educated in the transformation process.

Ecological cultural inheritance and the continuation of ecological education. In the field of art education, if the thinking mode of production culture inheritance can be well applied, it will be very enlightening for art education. So, we can think of ecological education. Ecological education is the original starting point and expectation for education. This education model can achieve objective and rational education fusion development on the basis of inheriting a large number of excellent traditional cultures. It can be combined with the current situation to create a self-creation of a development model. We can say it is a relatively objective and rational education model with local conditions. Ecological education is based on humanistic thought, and inherits a large amount of philosophical thinking system in traditional Chinese art. It has the essence of harmonious coexistence 
between human and nature in the Chinese philosophical thinking system. At the same time, it also absorbs some views in the western art philosophy system and gives full play to the initiative of selfcreation to seek the life art in the art life. Under the development of this education model, people can achieve the cultural significance of combining with natural aesthetics in the field of culture and art, which endows art education with humanistic care. In terms of cultural inheritance in the education transformation of Chinese art, eco-education can provide a good idea in this transformation process, which is an education model combining modern art education with modern society, and can also explore a new direction for the development of Chinese art education.

\section{Conclusion}

To sum up, Chinese art education has achieved the transformation of talent cultivation goals and methods. This is a new attempt at the education model of future art. In the new education model of art, cultural inheritance should be constantly improved and improved in the future development process. Only in this way can we bring new development opportunities for the education transformation of Chinese art.

\section{References}

[1]. Gao Changmiao. On the inheritance of national culture in the process of education in university art [J]. Education exploration. 2014 (09).

[2]. Liang Jiu. A perspective of the progressive development of Chinese art education [J]. art education.2017(17).

[3]. Yuan Epee, Wen Jing, Pang Jie. On cultural inheritance in the transformation of Chinese art education $[\mathrm{J}]$. Journal of southeast university (philosophical and social science edition). 2009 $(01)$. 